\title{
Design of an Anti-Chip Cover for Machine Tools
}

\author{
Pang Yong \\ Xi'an Aeronautical Polytechnic Institute, Department of Aviation Manufacturing Engineering \\ 500 Yingbin Road, Yanliang District, Xi’an, China \\ Corresponding author: 348444234@qq.com
}

Keywords: machine tool, workbench, active anti chip bar, tongue depressor, anti-chip cover, anti-chip rubber sheath, gear, revolving shaft

\begin{abstract}
This design proposes an anti-chip cover used on the workbench of machine tool, including a cover plate, a plurality of active anti chip bars penetrating the interior of cover, a revolving shaft that penetrates the interior of the cover and active anti chip bar, and a plurality of tongue depressors and tongue depressor bodies installed on the revolving shaft. The design can be used to cover the workbench of machine tool. Only simple adjustment is needed to adjust the edge shape of the active anti chip bar so that it fits the outer contour shape of the workpiece or fixture mounted on the machine tool. Then, the position of the active anti-chip bar can be locked. There is no need for multiple anti chip covers in fixed shape when the machine tool is installed with different workpieces and fixtures, which solves the problem that multiple anti chip covers with different edges are needed if there is need to cover the workbench surface with anti chip cover. So far, the design has applied for Chinese national patent on March 17, 2016. The patent number is 201610153703.7 and it was awarded China National Invention Patent on December 26, 2017.
\end{abstract}

\section{INTRODUCTION}

In the field of machinery manufacturing, all machine tools with workbenches, including milling machines, planers, drilling machines and boring machines, are equipped with T-slots to clamp fixtures and workpieces. However, during cutting work of machine tool, chips will fall on the workbench and even the T-slot. It is particularly inconvenient to clean chips in the T-slot, so people cover a piece of sheet material on the working surface to make the cleaning work easier. Nevertheless, due to the need to install fixtures or workpieces in different shapes on the machine tool, a very large number of sheet materials are required to make the sheet material exactly linked up with the edge of the workpiece or fixture, resulting in waste. Moreover, to meet the geometric tolerance or size requirements of clamping workpiece or directly installed workpiece, the workpiece or fixture must be directly mounted on a clean workbench surface. Thus, design of an anti chip cover installed on the machine tool workbench so that the edge of the anti chip cover will change with the shape of the fixture and workpiece mounted on the machine tool is the problem this design aims to solve.

\section{SPECIFIC DESIGN PROGRAM}

The technical problem to be solved in this design is to make the edge shape of the anti chip cover change with different fixtures or workpieces installed.

Regarding technical scheme of the present design, the anti-chip cover for machine tools is characterized in that: the interior of the cover (1) is a cavity structure, a plurality of active anti chip bars (2) penetrate through the flat hole groove in the front of the cover (1). The revolving shaft (5) penetrates through the elongated slot on the side of the cover (1). The revolving shaft (5) has a plurality of slot holes with rectangular cross section in size consistent with that of tongue depressor body (8). Each slot hole is exactly located in the middle of each active anti chip bar (2). The interior of the slot hole on the revolving shaft (5) is equipped with two tongue depressors (7) in the upper 
and lower position, tongue depressor body(8) and tongue depressor assembly with three springs (9) respectively in the upper and lower positions. The empty head set of the revolving shaft is installed with gears (4), the empty tail set is covered with sleeves (6). The head end face of the active anti chip bar (2) has holes. The hinge pin 1 (10) penetrates into the hole, the threaded bushing (13) fixes the hinge pin 1 (10) in the hole, the column (11) is fixed on the hinge pin 1 (10) and connected with column chain plate (12) through the hinge pin 2 (16), chain link 1 (14), chain link 2 (15) and spring 1 (17). The active anti chip bar is wrapped with anti chip rubber sheath (3) at the head.

The four corners of the cover (1) are provided with four protrusions. The protrusions are provided with threaded holes for fastening to the workbench through screws. A rack is provided on one side of the flat groove of the cover (1) for meshing with gear (4). The rack length is between $100 \mathrm{~mm}$ and $2 \mathrm{~m}$ depending on the size of the machine tool workbench. The upper surface of the cover (1) is smooth and flat.

The rear part of the active anti chip bar (2) has a through elongated slot, the upper and lower sides of the elongated slot are in jagged structure, and the active anti chip strip (2) has a semicircular notch at the head.

The revolving shaft (5) is provided with a plurality of flat slot holes. The position of the flat slot holes corresponds to that of the active anti chip bar, and the length of the flat slot hole is $5 \sim 15 \mathrm{~mm}$ less than the width of the active anti chip bar.

The gear (4) is provided with hexagonal protrusions, and the inner hole is a plain hole to fix empty set on the revolving shaft (5).

The length of the tongue depressor body (8) is $5 \sim 15 \mathrm{~mm}$ less than the width of the active anti chip bar (2). A T-slot with a high bottom is provided on the upper and lower sides. The bottom of the T-slot is provided with 3 cylindrical holes. The tongue depressor body is internally provided with a spring (9), and the tongue depressor (7) springs up under the action of the spring (9).

The tongue depressor (7) has a convex cross section and a semicircle top.

The anti chip rubber sheath (3) is made of rubber material and has a cavity structure inside. It can be located on the front of the active anti chip bar (2) to cover the tongue depressor assembly.

The present invention can be conveniently used to cover the machine tool workbench. The edge shape of the anti-chip cover can be adjusted according to the shape of machine vise, dividing head and special fixture installed on the machine tool. Also, corresponding chip cleaning mechanism can be installed on it, demonstrating its easy operation and strong practicability.

\section{INSTALLATION LOCATION AND USAGE OF THE DEVICE}

This device is an anti chip cover for machine tools (including such metal cutting machine tools with flat workbench as milling machines, boring machines, drilling machines, and planers).

To use the device, fix the cover (1) on the machine tool workbench with the fastening screws. If the workpiece and the fixture (including vise, dividing head, etc.) are installed in the middle of the machine tool, two symmetrical anti chip covers for machine tool need to be installed at this time. Meanwhile, rotate the revolving shaft (5), gear (4) and pull the active anti chip bar (2) so that the front of the active anti chip bar (2) clamps the workpiece or fixture through the anti chip rubber sheath (3). Then, adjustment of anti chip cover for machine tool is finished.

When chip drops from the surface of the anti chip cover, it can be cleaned manually or by installing an automatic chip cleaning mechanism.

\section{INTELLECTUAL PROPERTY STATUS}

For this design, a patent application entitled "Anti Chip Cover for Machine Tools" with application number 201610153703.7 was submitted to the State Intellectual Property Office of P.R.C on March 17, 2016, and it was awarded patent right on December 26, 2017. 


\section{DRAWING DESCRIPTION}

Fig. 1 is an overall axonometric drawing of the anti-chip cover.

Fig. 2 is a partial enlarged drawing of A part in Fig. 1.

Fig. 3 is a partial enlarged drawing of $\mathrm{B}$ part in Fig. 1.

Fig. 4 is a partial enlarged drawing of $C$ part in Fig. 1.

Fig. 5 is a partial enlarged drawing of E part in Fig. 7.

Fig. 6 is a partial enlarged drawing of D part in Fig. 7.

Fig. 7 is an axonometric drawing of the cover part.

Fig. 8 is an axonometric drawing of the cover part at another angle.

Fig. 9 is an isometric drawing of some part of the anti-chip cover.

Fig. 10 is an isometric drawing of some part of the anti-chip cover.

Fig. 11 is a partial enlarged drawing of F part in Fig. 10.

Fig. 12 is a partial enlarged drawing of G part in Fig. 9.

Fig. 13 is a partial enlarged drawing of $\mathrm{H}$ part in Fig. 9.

Fig. 14 is an isometric drawing of some part of the anti-chip cover.

Fig. 15 is a partial enlarged drawing of J part in Fig. 14.

Fig. 16 is a partial enlarged drawing of I part in Fig. 14.

Fig. 17 is a partial enlarged drawing of K part in Fig. 20.

Fig. 18 is a partial enlarged drawing of L part in Fig. 20.

Fig. 19 is an exploded drawing of L part in Fig. 20.

Fig. 20 is an isometric drawing of some part of the anti-chip cover.

Fig. 21 is an isometric drawing of some part of the anti-chip cover

Fig. 22 is a partial enlarged drawing of $U$ part in Fig. 22

Fig. 23 is a partial enlarged drawing of T part in Fig. 21

Fig. 24 is an isometric drawing of some part of the anti-chip cover

Fig. 25 is an isometric drawing of some part of the anti-chip cover

Fig. 26 is a partial enlarged drawing of P part in Fig. 25

Fig. 27 is a partial enlarged drawing of V part in Fig. 21

Fig. 28 is an isometric drawing of some part of the anti-chip cover

Fig. 29 is an isometric drawing of some part of the anti-chip cover

Fig. 30 is a partial enlarged drawing of R part in Fig. 29

Fig. 31 is an exploded drawing of part of the anti-chip cover

Fig. 32 is an axonometric drawing of the retracted active anti chip bar of the anti chip cover

Fig. 33 is an axonometric drawing of active anti chip bar part.

Fig. 34 is a partial enlarged drawing of W part in Fig. 33;

Fig. 35 is a partial enlarged drawing of Q part in Fig. 33;

Fig. 36 is an isometric drawing of the cover (1) part

Fig. 37 is a partial enlarged drawing of I part in Fig. 36

In the drawing:

1. cover; 2. active anti chip bar; 3 . anti chip rubber sheath; 4 . gear; 5 . revolving shaft; 6 . sleeve 1 ;

7. tongue depressor; 8 . tongue depressor body; 9 . tongue depressor spring; 10 . hinge pin $1 ; 11$. column $1 ; 12$. column 2 ; 13 . threaded bushing; 14 . chain link 1; 15. chain link 2; 16 . hinge pin $2 ; 17$. spring 1. 


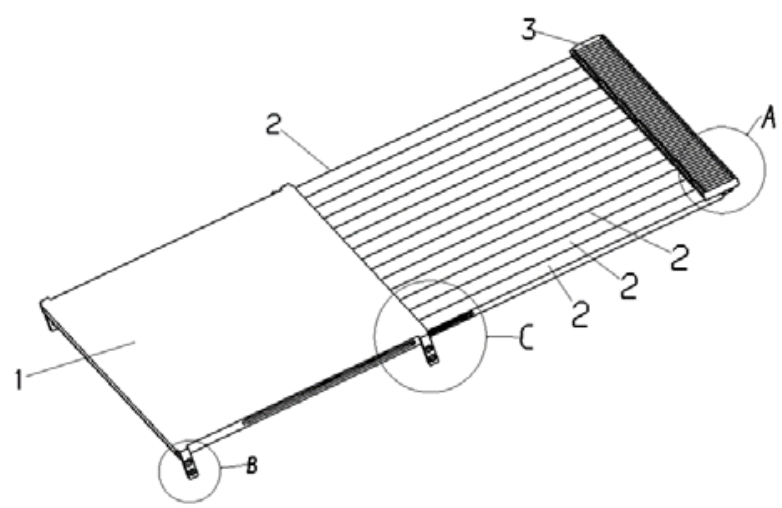

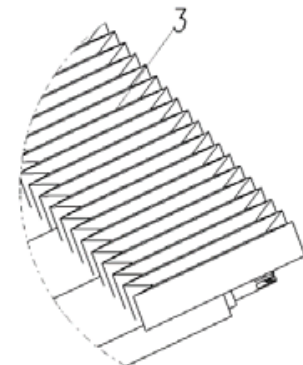

Fig.2

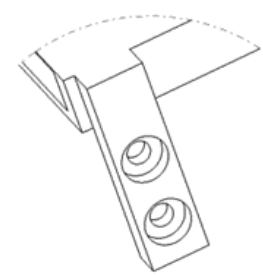

Fig.3

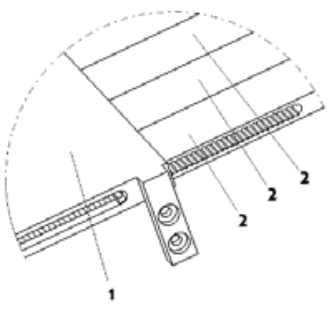

Fig.4



Fig.5
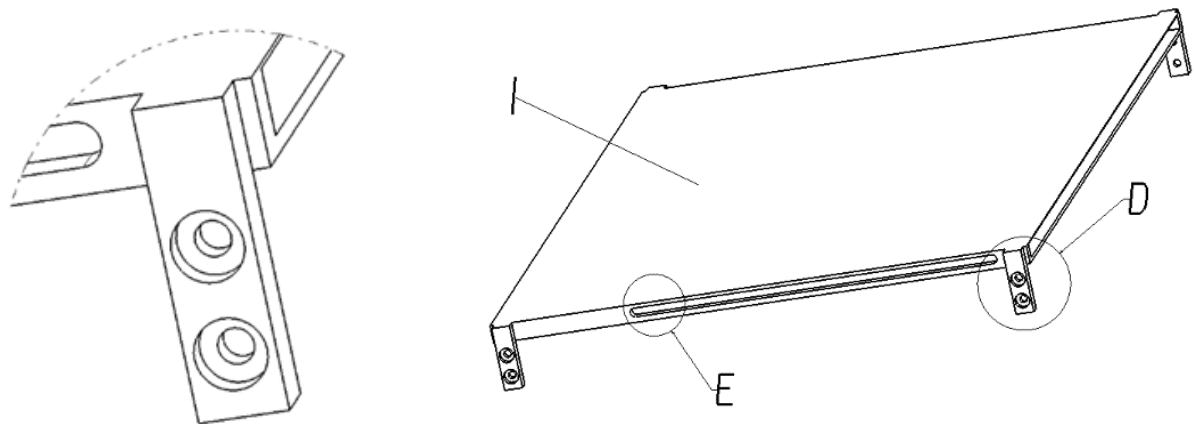

Fig.6

Fig.7

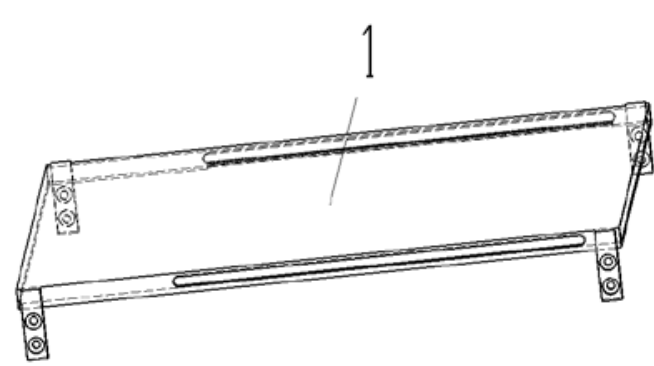

Fig.8

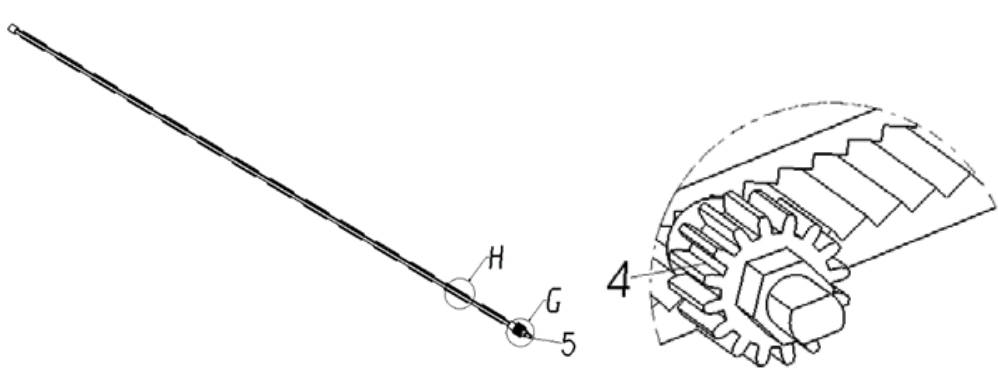

Fig.9

Fig.10



Fig.11

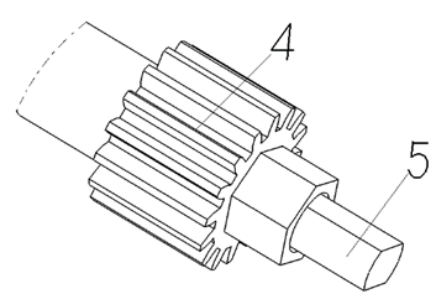

Fig.12

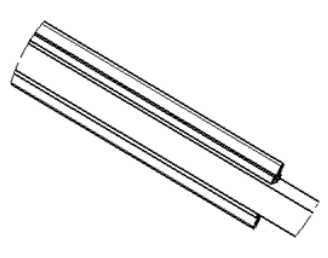

Fig.13 


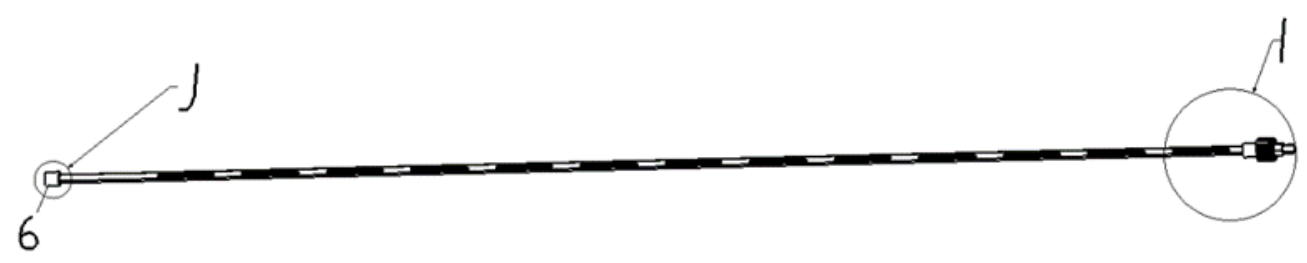

Fig.14

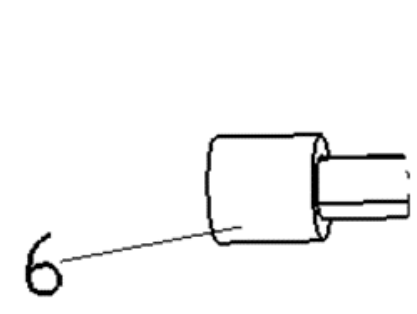

Fig.15

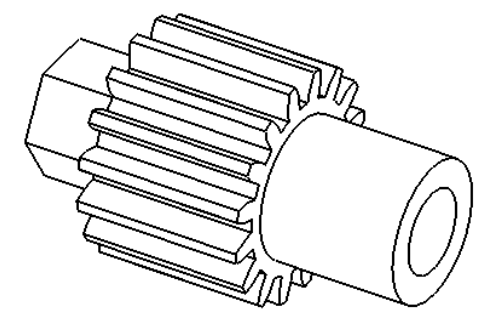

Fig.17

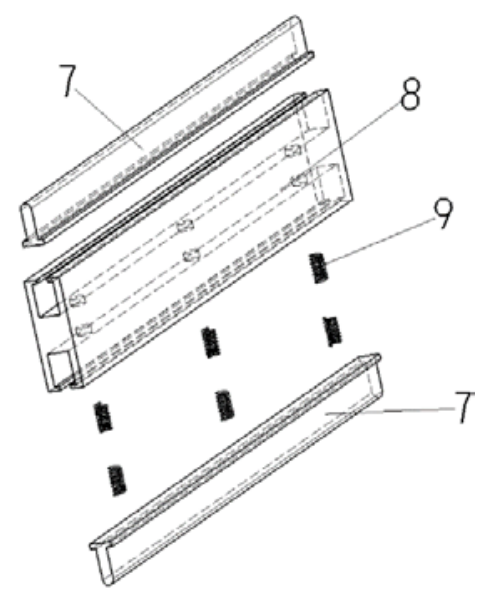

Fig.19

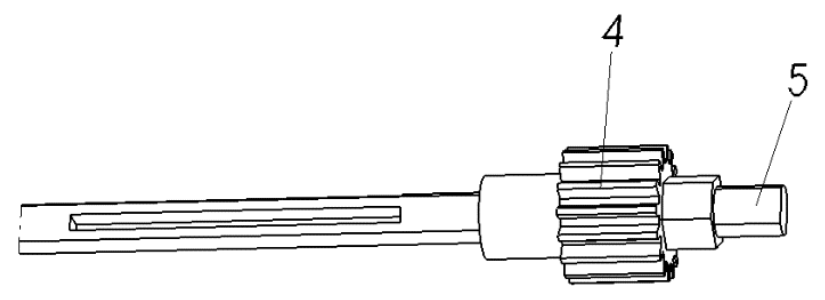

Fig.16

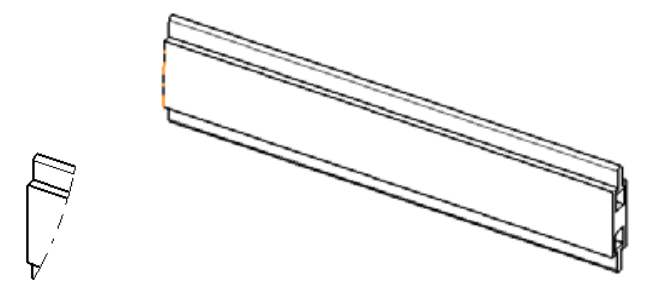

Fig.18



Fig.20



Fig.21 


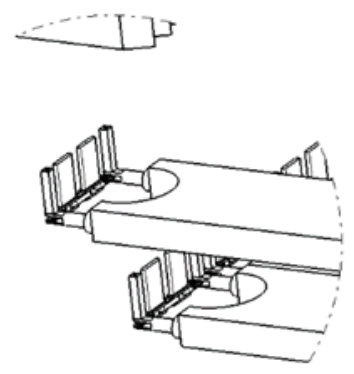

Fig.22

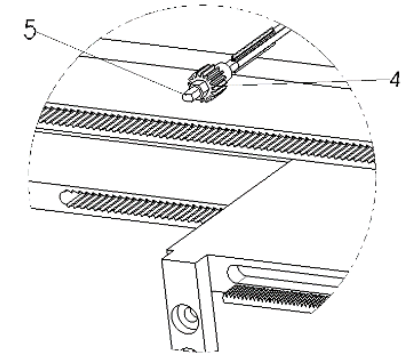

Fig.23

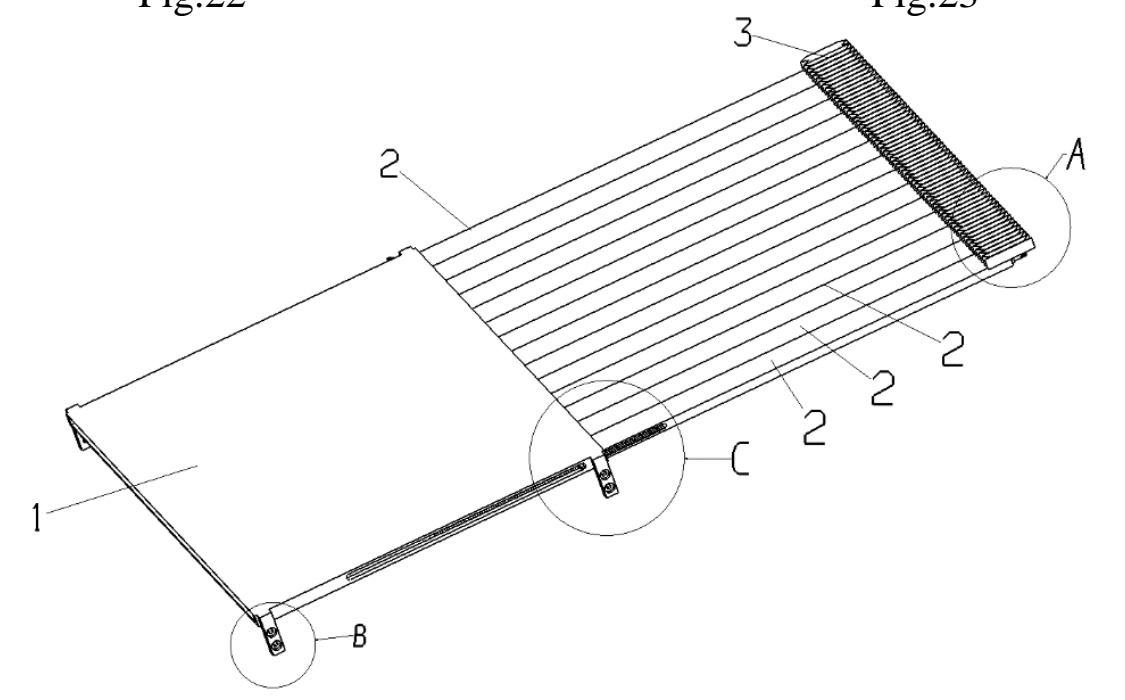

Fig.24

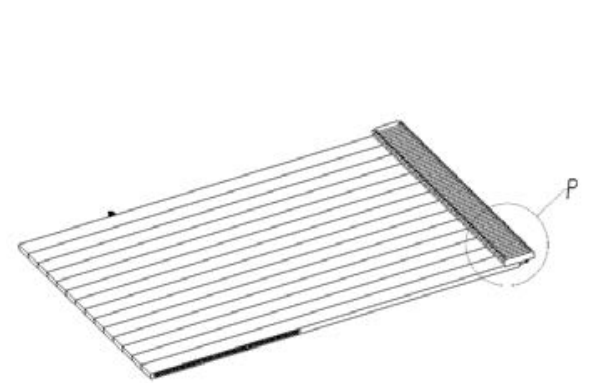

Fig. 25

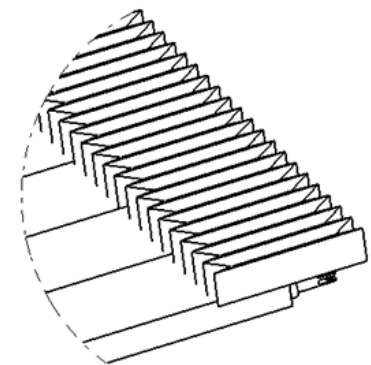

Fig.26

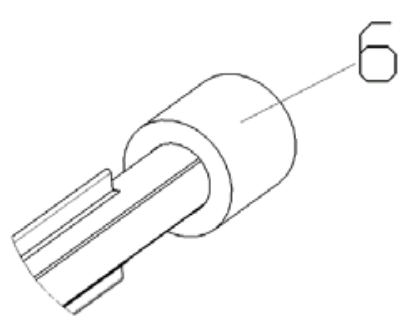

Fig.27

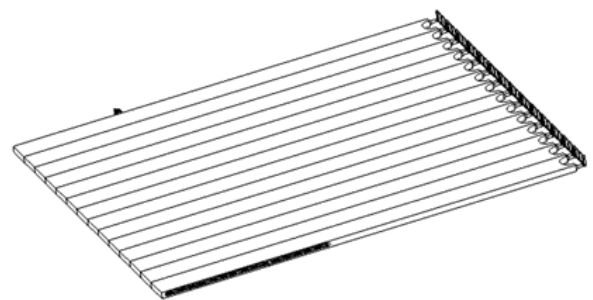

Fig.28

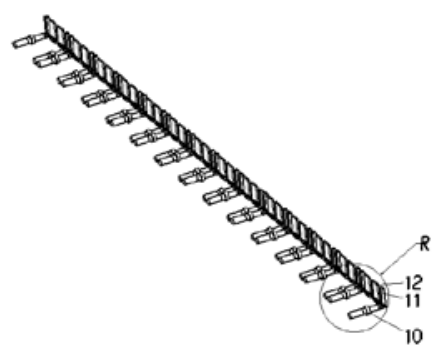

Fig.29 




Fig.30

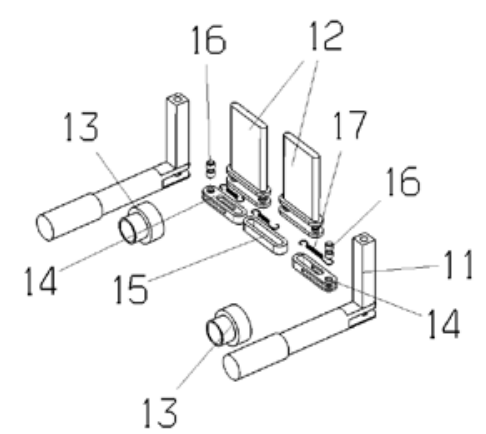

Fig.31

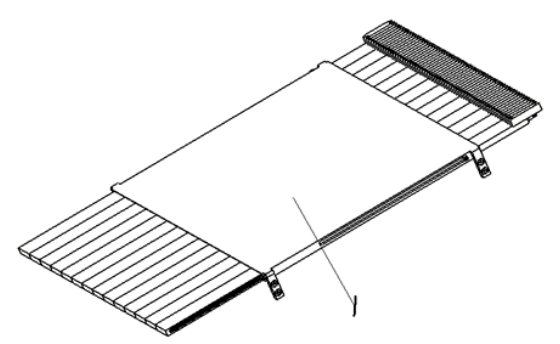

Fig.32

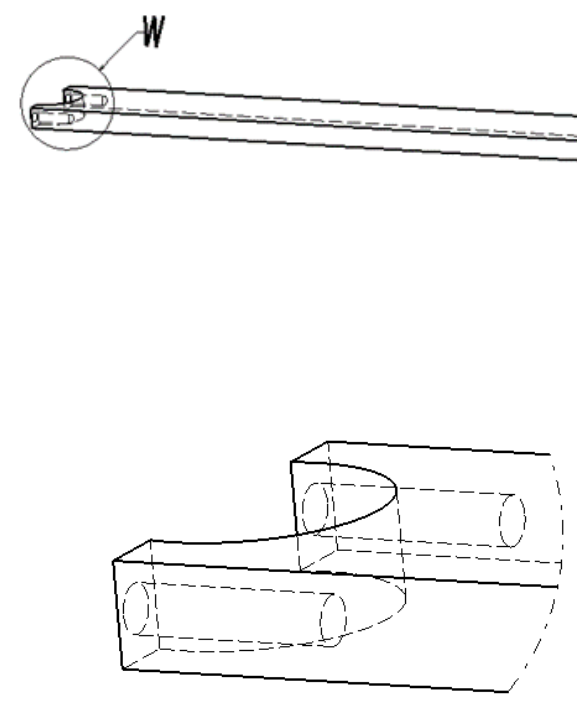

Fig.34

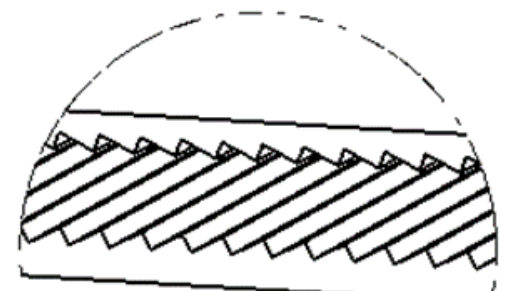

Fig.35

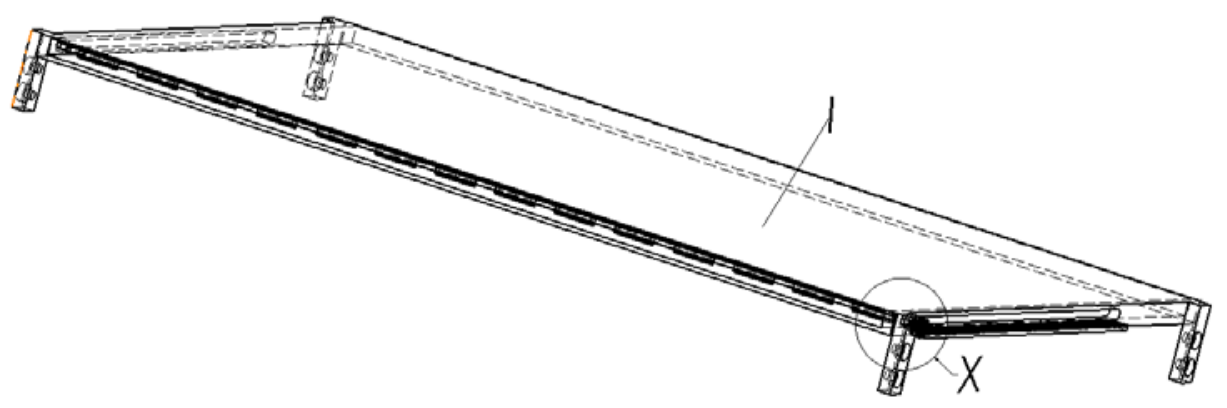

Fig.36 


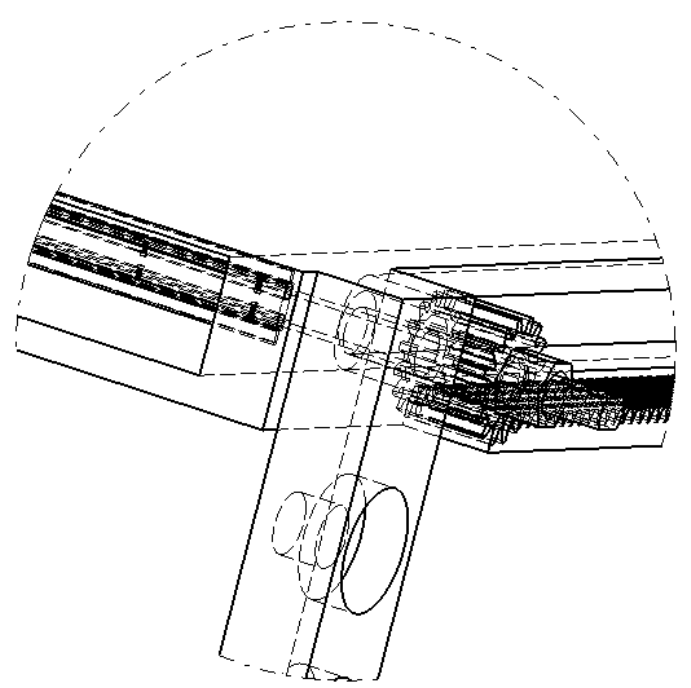

Fig.37

\section{CONCLUSION}

All machine tools with workbench including CNC milling machine, plain milling machine, boring machine will produce a large number of chip during machining. As the workbench is clamped with parts and fixtures of different shapes, sizes, cover of different shapes and sizes is needed to better cover the workbench. The machine tool cover in this design can adapt to anti chip requirements for installation of different fixture, parts after flexible adjustment of such parts as active anti chip cover, anti chip rubber sheath based on requirements of different fixture and parts, which lays a good foundation for subsequent automatic chip removal design of milling machines.

\section{REFERENCES}

[1] Design of an Anti Chip Cover for Machine Tools [P], China, Invention Patent, patent number: ZL 201610153703.7, Publication date: 2017

[2] Guo Hongxing, Mechanical Design Foundation [M] Xi'an, Xi'an Electronic Science \&Technology University Press 2006

[3] Deng Zhaoming, Mechanical Design Foundation [M], Beijing, Higher Education Press, 2000

[4] Huang Senbin, Mechanical Design Foundation [M], Beijing Mechanical Industry Press, 2001

[5] Yang Kezhen, Mechanical Design Foundation [M], Higher Education Press, 2006

[6] Sun Xueqiang, Mechanical Machining Technology [M], Mechanical Industry Press, 2004

[7] Jiang Peidong, Hydraulic and Pneumatic Technology[M], Higher Education Press, 2000

[8] Xu Jinkang, Mechanical Design [M], Higher Education Press, 2001 